\title{
Development and characterization of Rift Valley fever virus-like particles
}

\author{
Y.T. Li ${ }^{1,2,3 *}$, C.L. Wang ${ }^{1,2 *}$, X.X. Zheng' ${ }^{2}$, H.L. Wang ${ }^{2}$, Y.K. Zhao ${ }^{2}$, W.W. Gai ${ }^{2,4}$, \\ H.L. Jin ${ }^{5}$, Y.W. Gao' ${ }^{2}$ N. Li ${ }^{2}$, S.T. Yang' ${ }^{2}$ and X.Z. Xia ${ }^{1,2}$ \\ ${ }^{1}$ College of Animal Science and Technology, Shihezi University, Shihezi, China \\ ${ }^{2}$ Institute of Military Veterinary Medicine, Academy of Military Medical Science, \\ Changchun, China \\ ${ }^{3}$ College of Animal Science, Henan Institute of Science and Technology, \\ Xinxiang, China \\ ${ }^{4}$ College of Veterinary Medicine, Jilin University, Changchun, China \\ ${ }^{5}$ Changchun SR Biological Technology Co., Ltd., Changchun, China \\ *These authors contributed equally to this study. \\ Corresponding authors: S.T. Yang / X.Z. Xia \\ E-mail: yst62041@163.com / xiaxzh@cae.cn \\ Genet. Mol. Res. 15 (1): gmr.15017772 \\ Received October 2, 2015 \\ Accepted December 4, 2015 \\ Published March 24, 2016 \\ DOI http://dx.doi.org/10.4238/gmr.15017772
}

ABSTRACT. Rift Valley fever (RVF) is an acute, febrile zoonotic disease that is caused by the RVF virus (RVFV) and spread by arthropod vectors. RVF is currently prevalent in Africa and the Arabian Peninsula, and causes substantial economic losses. Furthermore, this disease poses a serious threat to animal and human health in regions worldwide, making it a serious public health concern. However, RVFV vaccines for human use are still unavailable, and hence there is an urgent need for novel efficient vaccines against RVFV. Vaccine preparation techniques have become a crucial factor in developing new vaccines. In the current study, the $\mathrm{N}$ and $G$ protein genes of RVFV were inserted into the pFastBacDual baculovirus expression vector downstream of the $\mathrm{pP} 10$ and $\mathrm{pPH}$ promoters. The resultant recombinant vector, pFastBacDual-S-M, was transfected into Sf9 insect cells by lipofection. The recombinant baculovirus, named rBac-N-G, 
was retrieved and infected into Sf9 insect cells to generate RVFV viruslike particles (VLPs). Using polyclonal antibodies against RVFV proteins in immunofluorescence and western blot analyses, we positively identified the presence of the RVFV proteins in VLP preparations. Sucrose density gradient centrifugation and transmission electron microscopy revealed that the morphology of the RVFV VLPs was consistent with previous reports of RVFV virions. This study describes a technique for efficient production of RVFV VLPs, and has laid the foundation for future VLP-based RVFV vaccines.

Key words: Baculovirus expression system; Rift Valley fever virus; Vaccine preparation; Virus-like particle

\section{INTRODUCTION}

Rift Valley fever (RVF) is a viral infectious disease spread by mosquitoes. RVF mainly infects ruminants such as sheep, goats, and cattle, and can cause miscarriage in pregnant animals as well as death in young animals. RVF virus (RVFV) was first isolated from a survey of a sheep disease outbreak in the Rift Valley in Kenya by Daubney and Hudson in 1931. Humans are commonly susceptible to RVF, and the primary clinical manifestations of RVFV infection include encephalitis and retinitis among other symptoms. Individual cases in humans can present with symptoms of hemorrhagic fever, and severe cases can lead to death (Woods et al., 2002; LaBeaud et al., 2008; Seufi and Galal, 2010). RVFV has been classified as a biological warfare agent by the World Health Organization (WHO), and as a Class A pathogen by the Centers for Disease Control and Prevention and the Department of Agriculture in the United States (Ikegami, 2012). Moreover, the World Organization for Animal Health has categorized RVF as a Class A statutory reporting animal disease. In China, RVF has been included in the list of 13 exotic animal diseases under priority prevention by the National Medium- and Long-Term Plan for Animal Disease Prevention and Control (2012-2020).

RVF commonly occurs in rural and pastoral areas, and has strict seasonality, which often begins in late May or early June and ends in late November to December. Lambs, kid-goats, and calves are the primary sources for human RVFV infection, whereas patients and other animal hosts can also serve as sources for human infection. The blood, body fluids, viscera, and organs of RVFV-infected animals are all contagious. Human cases usually occur 1-2 weeks after the onset of infection in animals. RVF has significant occupational effects, which are commonly observed in herders, veterinarians, butchers, and farmers. Additionally, a high incidence of RVF has been observed in RVFV researchers. Furthermore, this disease can be both endemic and epidemic. For instance, an epidemic outbreak of RVF killed 100,000 sheep and infected 20,000 individuals in Kenya from 1950 to 1951 (Mundel and Gear, 1951). Moreover, an epidemic outbreak of RVF in Egypt led to animal infections in $25-50 \%$ of sheep, cattle, and camels. Meanwhile, there were 18,000 patients diagnosed with RVFV infection, and 598 patients were killed. Alarmingly, the infection rate of RVFV has reached 35\% in certain areas (Conraths et al., 2013). A total of 34 cases of RVF were reported in six areas of Mauritania from September 16, 2012 to October 30, 2012. These resulted in 17 deaths, accounting for a high mortality rate of $50 \%$ (WHO, 2012). It is also worth noting that RVF crossed the Red Sea in September 2000. As a consequence, the epidemic situation 
was found for the first time outside of the traditional endemic region of the Arabian Peninsula (Saudi Arabia and Yemen). This situation has increased the threat of RVF spread and propagation towards other regions of the world such as Asia and Europe (Ahmed et al., 2009).

RVFV belongs to the Phlebovirus genus of the Bunyaviridae family. The virus is enveloped, spherical, and has a diameter of approximately $80-120 \mathrm{~nm}$. The viral envelope is coated with surface glycoprotein projections of $10 \mathrm{~nm}$ in diameter, while the nucleic acids that comprise the viral genome are located within the nucleocapsid. The nucleic acids that make up the RVFV genome are single-stranded antisense RNA molecules that consist of small (S), medium (M), and large (L) segments. The $\mathrm{S}$ segment, which is comprised of 1690 nucleotides (nt), encodes the $\mathrm{N}$ and NSs proteins; the M segment (3885 nt) encodes the G2 (Gn), G1 (Gc), and NSm proteins; and the L segment (6404 nt) encodes the L protein (an RNA-dependent RNA polymerase). The RVFV N and $\mathrm{L}$ proteins are responsible for viral replication and transcription. $\mathrm{G} 2$ and $\mathrm{G} 1$ are glycoproteins that enter the viral envelope to form a ribonucleoprotein complex (RNP) with the $N$ protein. Additionally, the RNP and L protein jointly package the viral particle. NSm and NSs are nonstructural proteins (Ikegami, 2012).

Presently, commercialized vaccines and special antiviral drugs are unavailable for human or animal use against RVF outside of traditionally endemic countries. Therefore, there is an urgent need for countermeasures to cope with RVFV that has been accidentally or intentionally introduced into non-endemic countries or regions. RVF vaccines used for animal vaccination in the endemic areas mainly include live-attenuated vaccines (Caplen et al., 1985; Muller et al., 1995; Kortekaas, 2014), inactivated vaccines (Randall et al., 1962; Rusnak et al., 2011), and genetically engineered vaccines (Kortekaas et al., 2010, 2012; López-Gil et al., 2013). These vaccines have inherent drawbacks, and no RVF vaccines for human use have been approved by the U.S. Food and Drug Administration. Although inactivated vaccines are safe, the virus cultures require certain biosafety considerations, and the dose must be increased repeatedly. Attenuated live vaccines are associated with biosafety risks that include the reversion to toxicity despite their high immunogenicity. Hence, from a biosafety perspective, inactivated and attenuated vaccines are unsuitable for immunization in non-endemic areas. Moreover, there is a serious lack of novel efficient RVFV vaccine strategies. Virus-like particle (VLP) vaccines are characterized by their high safety and immunogenicity, and thereby are great prospects for development against different viruses. In the current study, we investigated the use of a baculovirus expression system to create RVFV VLPs, thus laying the foundation for developing new VLP-based vaccines for RVFV.

\section{MATERIAL AND METHODS}

\section{Cells and viruses}

DH5 $\alpha$ competent cells were purchased from TaKaRa (Japan). Trans1-T1 competent cells were obtained from TransGen Biotech (Beijing, China). Escherichia coli DH10Bac competent cells, the pFastBacDual Baculovirus Expression Vector, the pUC57-Simple-M (recombinant plasmid containing RVFV structural genes M), pUC57-Simple-S (recombinant plasmid containing RVFV structural genes S), and the Spodoptera frugiperda 9 (Sf9) insect cell line were provided by the Laboratory of Military Veterinary Institute, Chinese Academy of Military Medical Sciences (Changchun, China). The cells were cultured using SF900 II serum-free medium purchased from Gibco (Carlsbad, CA, USA), and were incubated at $27^{\circ} \mathrm{C}$. 


\section{Codon optimization}

The gene data for the RVFV ZH501 strain (GenBank accession No. DQ380154.1 for the $S$ segment and DQ380208.1 for the M segment) was retrieved from the National Institutes of Health $(\mathrm{NIH})$ National Center for Biotechnology Information (NCBI) website (www.ncbi.nlm.nih. gov/). The nucleotide sequences of the open-reading frames (ORF) were analyzed for the $S$ segment-encoded $\mathrm{N}$ protein and the M segment-encoded $\mathrm{G}$ protein. Specifically, the 738-nt ORF of $\mathrm{S}$ encodes for the 245 -amino acid $\mathrm{N}$ protein with a molecular weight of $25 \mathrm{kDa}$, and the M ORF encodes for the 507 amino acids $\mathrm{G} 1$ protein $(65 \mathrm{kDa})$ and the 537 amino acids $\mathrm{G} 2$ protein ( $56 \mathrm{kDa})$. Codon optimization of the native ORF was performed using the GenScript Rare Codon Analysis Tool (Sangon, Shanghai, China, available at: http://www.genscript.com/cgi-bin/tools/rare_codon_ analysis) based on the baculovirus expression system. Restriction endonuclease cleavage sites were added upstream and downstream of the optimized sequences of $S(K p n l$ and $S p h l)$ and $M$ (Sall and Notl). The S and M gene sequences were synthesized by Sangon, and the synthetic sequences were inserted into the pUC57-Simple plasmid, namely pUC57-Simple-S and pUC57Simple-M, respectively.

\section{Generation of recombinant baculoviruses}

The pUC57-Simple-S plasmid and pFastBacDual baculovirus expression plasmid were double-digested with $K p n l$ and Sphl. Then, the $S$ segment and pFastBacDual were recovered, and the $\mathrm{N}$ gene was cloned directionally into the plasmid downstream of the pP10 promoter. The resultant recombinant pFastBacDual-S vector was transformed into Trans1-T1 competent cells, and then identified by restriction endonuclease digestion. The same approach was used to doubledigest pUC57-Simple-M and pFastBacDual-S plasmids with Notl and Sall. After recovery, the M segment was subcloned directionally into the pFastBacDual-S vector downstream of the $\mathrm{pPH}$ promoter to construct the recombinant $\mathrm{pFastBacDual-S-M}$ vector.

After validation, the recombinant $\mathrm{pFastBacDual-S-M}$ vector was transformed into $E$. coli DH10Bac competent cells. The transformed bacterial cells were cultured on solid LB medium containing X-gal and three antibiotics (kanamycin $50 \mathrm{ng} / \mathrm{mL}$, gentamicin $7 \mathrm{ng} / \mathrm{mL}$, and tetracycline $10 \mathrm{ng} / \mathrm{mL}$ ), and were incubated at $37^{\circ} \mathrm{C}$ for $48 \mathrm{~h}$. Positive clones were obtained by blue-white screening, and the screening was repeated twice. Then, the white colonies were selected and inoculated into LB broth containing the three aforementioned antibiotics. The culture was incubated at $37^{\circ} \mathrm{C}$ with shaking at $200 \mathrm{rpm}$ for $12 \mathrm{~h}$. Total genomic DNA was extracted from the resultant recombinant baculovirus, and the recombinant viral genome was identified by a PCR assay. The recombinant shuttle vector with positive correct identification results was named BacmidS-M. Plasmid DNA was extracted from the recombinant shuttle vector using the PureLink HiPure Plasmid Miniprep Kit (Axygen, Union City, CA, USA) in accordance with manufacturer instructions. The extracted plasmid DNA was used to transfect Sf9 cells.

The recombinant Bacmid-S-M shuttle vector that yielded correct positive identification results was transfected into Sf9 cells with Lipofectamine 2000 (Invitrogen, Carlsbad, CA, USA). Briefly, the transfection procedure was as follows: 1) the Sf9 cells were maintained in adherent culture conditions in the logarithmic growth phase prior to seeding on 6-well cell culture plates at $2.0 \times 10^{6}$ cells per well, and the cell cultures were then incubated statically at $27^{\circ} \mathrm{C}$ for $18-24$ h before transfection; 2) Lipofectamine 2000 (20 $\mu \mathrm{L}$ ) was added to $200 \mu \mathrm{L}$ serum-free Grace's 
medium without antibodies and was then mixed; 3) Bacmid-S-M plasmid (4 $\mu \mathrm{g}$ ) was added to 200 $\mu \mathrm{L}$ Grace's medium and was then mixed; 4) equal volumes of the plasmid and transfection reagent prepared in steps (2) and (3) were mixed by gentle pipetting, and the mixture was allowed to stand at room temperature for $15 \mathrm{~min} ; 5)$ the solution obtained from step (4) was added dropwise on the 6 -well plates prepared in step (1), and the plates were incubated at $27^{\circ} \mathrm{C}$ for $5 \mathrm{~h}$; and 6) the medium containing the transfection reagent was aspirated, and $2 \mathrm{~mL}$ complete Grace's medium containing double antibiotics and $10 \%$ serum was added, and the culture was incubated at $27^{\circ} \mathrm{C}$ for $72 \mathrm{~h}$ until the cells showed a cytopathic effect (CPE). The supernatant of the cell suspension was harvested, and the resultant recombinant baculovirus was named rBac-N-G.

\section{Sucrose density gradient centrifugation (SDGC)}

The Sf9 cells were infected with rBac-N-G at a multiplicity of infection (MOI) of 2. The culture was incubated at $27^{\circ} \mathrm{C}$ with $120 \mathrm{rpm}$ shaking in flasks for $96 \mathrm{~h}$. The cells were collected and centrifuged at $7000 \mathrm{rpm}$ at $4^{\circ} \mathrm{C}$ for $20 \mathrm{~min}$ to remove cells and cell debris. The supernatant was collected and centrifuged at $35,000 \mathrm{rpm}$ at $4^{\circ} \mathrm{C}$ for $120 \mathrm{~min}$. The precipitate was harvested and resuspended in phosphate-buffered saline (PBS). The suspension was then slowly added to the upper surface of a sucrose gradient $(20-40-60 \%$, w/v), and the mixture was centrifuged at 30,000 rpm at $4^{\circ} \mathrm{C}$ for $120 \mathrm{~min}$. A white virus belt was collected between the surfaces of 40 and $60 \%$ sucrose, and was resuspended in PBS. The suspension was centrifuged at 30,000 rpm for $90 \mathrm{~min}$ to remove the sucrose and to obtain VLPs. The resultant RVFV VLPs were identified and validated by western blot and electron microscopy analyses.

\section{Western blot}

The RVFV VLPs were mixed with $5 X$ loading buffer, heated at $95^{\circ} \mathrm{C}$ for $5 \mathrm{~min}$, and loaded onto polyacrylamide gels for sodium dodecyl sulfate-polyacrylamide gel electrophoresis. After electrophoresis, the proteins were transferred to a $0.22-\mu \mathrm{m}$ polyvinylidene fluoride membrane and blocked at room temperature for $1 \mathrm{~h}$ with a $0.5 \%$ Tween-20 membrane blocking solution containing $5 \%$ bovine serum albumin (Thermo, Waltham, MA, USA). Mouse polyclonal anti-RVFV-N (1:600 dilution, IBT BIO Services, Gaithersburg, MD, USA) or rabbit polyclonal anti-RVFV-MP12 (1:4000 dilution, IBT BIO Services) primary antibodies were incubated with the membrane for $16 \mathrm{~h}$ at $4^{\circ} \mathrm{C}$. After washing, goat anti-mouse (1:3000 dilution) or goat anti-rabbit (1:4000 dilution) horseradish peroxidase-labeled IgG secondary antibodies were added and incubated for $1 \mathrm{~h}$ at room temperature. A color reaction was then performed using the Super Signal West Dura Extended Duration Substrate (Thermo). The results were imaged and saved using the LAS-4000 System (Fujifilm, Tokyo, Japan).

\section{Indirect immunofluorescence}

$\mathrm{N}, \mathrm{G} 1$, and $\mathrm{G} 2$ protein expression in the RVFV VLPs was analyzed by an indirect immunofluorescence assay. Specifically, the Sf9 cells were infected with rBac-N-G at an MOI of 2 , and were incubated statically at $27^{\circ} \mathrm{C}$ for $72 \mathrm{~h}$. The supernatant was removed, and the cells were washed three times in PBS. Then, $100 \mu \mathrm{L}$ precooled $80 \%$ acetone $(\mathrm{v} / \mathrm{v})$ was added to each well, and the cells were incubated at $-20^{\circ} \mathrm{C}$ for $6 \mathrm{~h}$ to fix them. After three washes with PBST, 
the aforementioned anti-RVFV-N (1:600 dilution) or anti-RVFV-MP12 (1:4000 dilution) primary antibodies were added and the cells were incubated for $1 \mathrm{~h}$ at $37^{\circ} \mathrm{C}$. After three washes with PBST, the cells were incubated with goat anti-mouse or goat anti-rabbit fluoresce in isothiocyanatelabeled secondary antibodies at $37^{\circ} \mathrm{C}$ for $1 \mathrm{~h}$. After an additional three washes with PBST, the cells were observed under an inverted fluorescence microscope. The cells with specific green fluorescence were considered positive. Normal Sf9 cells treated following the same procedure, but without rBac-N-G, were used as a negative control.

\section{Visualization of the VLPs by transmission electron microscopy (TEM)}

The rBac-N-G-infected Sf9 cell lysate (after repeated freeze-thaw cycles) or purified VLPs were adsorbed to a metal mesh and stained with $1 \%$ phosphotungstic acid for 2-3 min. The residual staining solution on the mesh was removed using filter paper. Microscopic observation was performed using a JEM1200EXII TEM (JEOL, Tokyo, Japan).

\section{RESULTS}

\section{Codon optimization}

Rare codon optimization can significantly improve the efficiency of protein expression and VLP assembly in the baculovirus expression system. Therefore, the target genes herein were codon optimized. The occupancy rates of codons with different preferences before and after optimization were analyzed using the GenScript Rare Codon Analysis Tool. The numerical values 0-10 and 91-100 represent the codons with the lowest and highest frequency of use in the insect cells, respectively. In the $\mathrm{N}$ protein gene, $6 \%$ of the codons were rare prior to optimization, and the most preferred codons only accounted for $47 \%$ of the total codons (Figure $1 \mathrm{~A}$ ). All of the rare codons in the $\mathrm{N}$ gene were mutated into commonly used codons following optimization, and the proportion of the most preferred codons increased to $89 \%$ (Figure 1B). In the G protein gene, $6 \%$ of the codons were rare before optimization, and the most preferred codons only accounted for $37 \%$ of the total codons (Figure 1C). All of the rare codons were mutated to commonly used codons after optimization, and the proportion of the most preferred codons was increased to $60 \%$ (Figure 1D). The comparison of codons before and after optimization is presented in Table 1.

\section{Construction of recombinant Bacmid}

The $S$ and $M$ segments of RVFV were separately inserted into the pFastBacDual baculovirus expression vector, and positively transformed clones were identified by PCR. PCR amplification was performed using the universal primers for pP10 and pPH on the pFastBacDual plasmid, with pFastBacDual-S-M-RVFV serving as the template. The PCR results showed that the amplified fragment of the S segment was 1000 bp and that of the M segment was 3200 $\mathrm{bp}$, which were both in agreement with the expected fragment sizes (Figure 2). Additionally, nucleic acid sequencing data revealed that the target genes shared $100 \%$ homology with the expected protein genes, with no adverse mutations or nucleotide deletions. Taken together, the above results indicated that pFastBacDual-S-M-RVFV was constructed correctly, and was named Bacmid-S-M. 


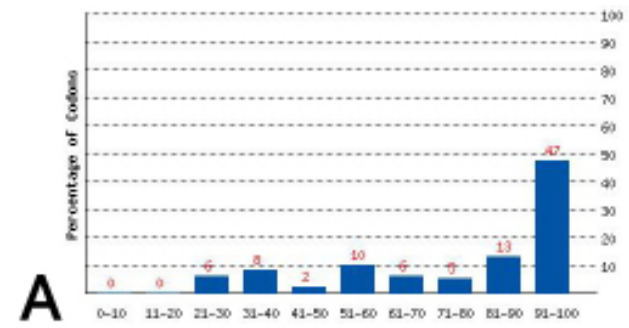

Native $\mathrm{N}$

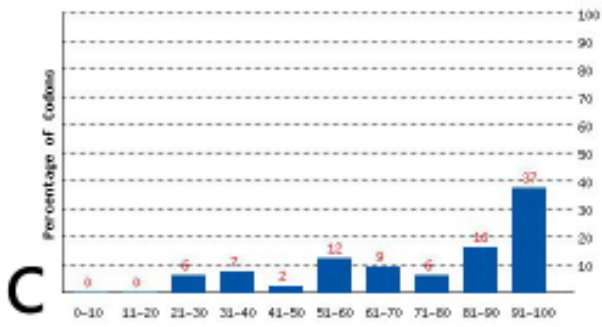

Native G

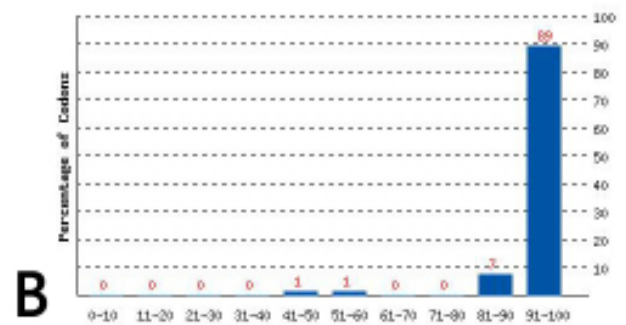

Codon-optimized $\mathrm{N}$

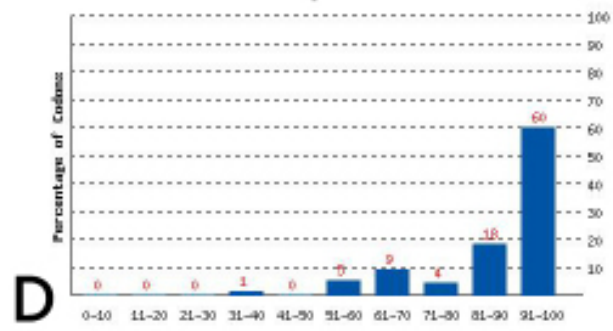

Codon-optimized G

Figure 1. Codon optimization of the $\mathrm{N}$ and $\mathrm{G}$ protein genes from Rift Valley fever virus. A. Rare codons in the $\mathrm{N}$ protein gene before optimization as predicted by GenScript. B. Rare codons in the N protein gene after optimization as predicted by GenScript. C. Rare codons in the G protein gene before optimization as predicted by GenScript. D. Rare codons in the $\mathrm{G}$ protein gene after optimization as predicted by GenScript.

Table 1. Comparison of parameters between native and codon-optimized nucleotide sequences for protein expression in Sf9 cells.

\begin{tabular}{l|c|c|c|c}
\hline Nucleotide sequence & Nucleotide length (nt) & Rare codon content & CAI & GC content (\%) \\
\hline Native N ORF & 738 & 0.06 & 0.73 & 49.94 \\
\hline Codon-optimized N ORF & 738 & None & 0.96 & 59.82 \\
\hline Native G ORF & 3204 & 0.06 & 0.70 & 46.13 \\
\hline Codon-optimized G ORF & 3204 & None & 0.87 & 53.10 \\
\hline
\end{tabular}

CAl: codon adaptation index; ORF: open-reading frame.

\section{Generation of recombinant baculovirus}

The recombinant Bacmid-S-M plasmid was transfected into Sf9 insect cells by lipofection. The culture was incubated at $27^{\circ} \mathrm{C}$ for $72 \mathrm{~h}$ until the cells showed $\mathrm{CPE}$ such as cell expansion, wall separation, suspension, aggregation, and fusion. The first-generation recombinant virus $\mathrm{rBac}-\mathrm{N}-\mathrm{G}$ was harvested when the rate of CPE reached $80 \%$ or higher. Then, rBac-N-G was transferred to a new monolayer culture of Sf9 insect cells, which were incubated for $72 \mathrm{~h}$, and the resultant virus was again harvested at a CPE rate of $80 \%$. The second-generation rBac-N-G was continuously passed to the third generation. The titer of $\mathrm{rBac}-\mathrm{N}-\mathrm{G}$ was determined using the BacPAK Baculovirus Rapid Titer Kit (TaKaRa), by which the titer of the third-generation rBac-N-G was found to be approximately $3 \times 10^{7}$ plaque forming units $(\mathrm{PFU}) / \mathrm{mL}$, whereas the titer of the first generation was relatively low $\left(2.6 \times 10^{5} \mathrm{PFU} / \mathrm{mL}\right)$. The Sf9 insect cells transfected with first-generation rBac-N-G 
showed no CPE at $48 \mathrm{~h}$, but did display CPE at $72 \mathrm{~h}$ after transfection. The second-generation rBac-N-G began to propagate substantially and the speed of CPE was significantly accelerated compared to that of first generation, and had a titer of $4.2 \times 10^{6} \mathrm{PFU} / \mathrm{mL}$. The titer tended to stabilize in the third generation, i.e., at $3 \times 10^{7} \mathrm{PFU} / \mathrm{mL}$. Compared to those transfected with the first two generations of $\mathrm{rBac}-\mathrm{N}-\mathrm{G}$, the Sf9 insect cells transfected with the third generation showed rapid and severe CPE. Additionally, significant CPE was observed for the third generation at $48 \mathrm{~h}$ after transfection, indicating that this generation of rBac-N-G could be used for further study.

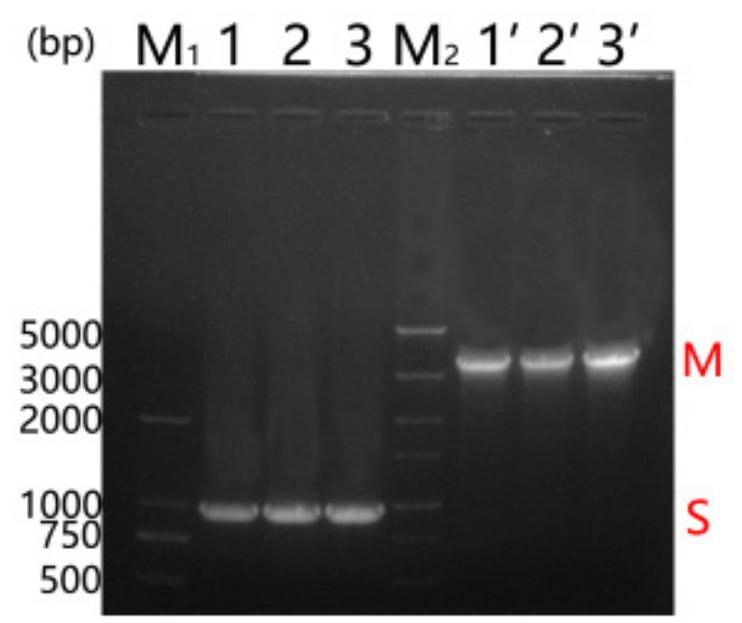

Figure 2. PCR amplification of the $S$ and $M$ gene segments from Rift Valley fever virus. Lane M1: Marker 2000; lane M2: Marker 5000; lanes 1, 2, and 3: S segment; lanes 1', 2', and 3': M segment.

\section{Western blot analysis of RVFV proteins}

To further confirm that the obtained VLPs were those of RVFV, a western blot analysis was performed using polyclonal antibodies against the $\mathrm{N}$ and MP12 proteins of RVFV. Using polyclonal anti-RVFV-N primary antibodies, a specific band was detected from the supernatant of rBac-NG-infected Sf9 cells as observed by western blot. This band had a molecular size of $25 \mathrm{kDa}$, which was in agreement with the size of the $\mathrm{N}$ protein $(25 \mathrm{kDa})$. No specific band was observed in the control group, indicating that the recombinant expression of the RVFV N protein was correct (Figure 3A). Additionally, three specific bands were detected by western blot with polyclonal antiRVFV-MP12 primary antibodies. These bands were approximately 65,56 , and $25 \mathrm{kDa}$, which were in agreement with the sizes of the $\mathrm{G} 1, \mathrm{G} 2$, and $\mathrm{N}$ proteins, respectively. This result indicates the presence of RVFV G1, G2, and N proteins in the VLPs that were prepared in this study (Figure 3B), thereby validating the obtained RVFV VLPs at the protein level.

\section{Immunofluorescence analysis of RVFV proteins}

Sf9 cells were infected with the prepared rBac-N-G for $72 \mathrm{~h}$ and then fixed with $80 \%$ cold acetone. An immunofluorescence assay was performed using polyclonal anti-RVFV-N and anti-RVFV-MP12 antibodies to detect RVFV N and G protein expression in Sf9 cells. High- 
intensity green fluorescence was observed in the rBac-N-G-infected Sf9 cells after incubation with polyclonal anti-N antibodies, whereas no green fluorescence was observed in the control cells (Figure 4A). Furthermore, the incubation of rBac-N-G-infected Sf9 cells with polyclonal anti-RVFVMP12 antibodies resulted in green fluorescence associated with the expression of N, G1, and G2 proteins of RVFV (Figure 4B). Taken together, these results demonstrate that the recombinant $\mathrm{rBac}-\mathrm{N}-\mathrm{G}$ virus produced herein expressed the target proteins.

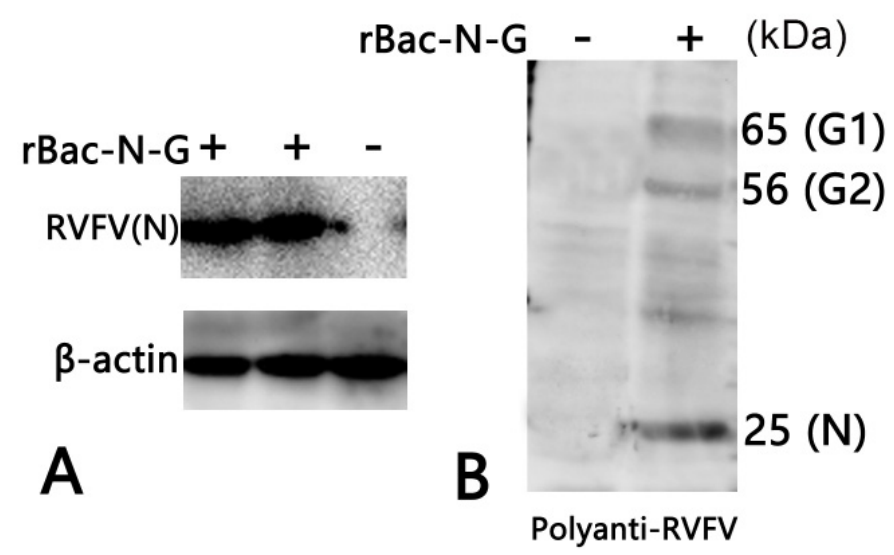

Figure 3. Western blot analysis of nucleocapsid (N) and total proteins from Rift Valley fever virus (RVFV MP12) in Sf9 cells after rBac-N-G infection. A. Identification of $\mathrm{N}$ protein with polyclonal anti-RVFV-N primary antibodies; + for rBacN-G-infected Sf9 cells $G$ and - for negative Sf9 cells. B. Identification of total proteins with polyclonal anti-RVFV-MP12 primary antibodies, including G1 (65 kDa), G2 (56 kDa), and N (25 kDa); + for rBac-N-G-infected Sf9 cells and - for negative Sf9 cells.

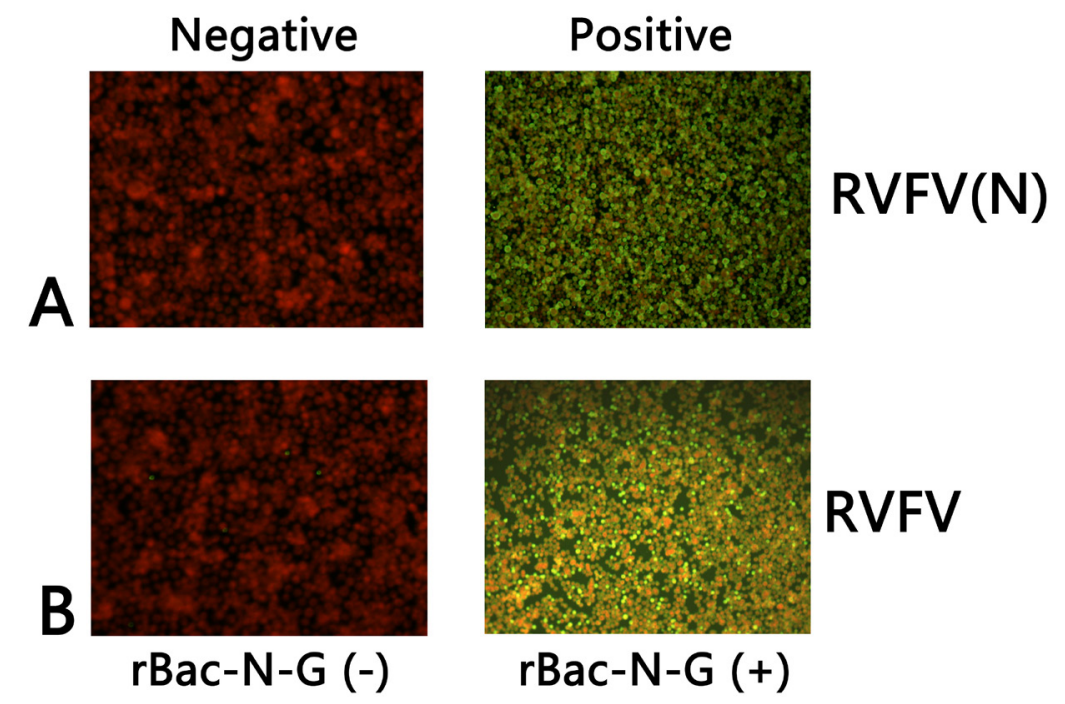

Figure 4. Immunofluorescence analysis of nucleocapsid (N) and total proteins from Rift Valley fever virus (RVFV) in Sf9 cells after rBac-N-G infection. A. Identification of N protein with polyclonal anti-RVFV-N primary antibodies; left negative Sf9 cells; right - rBac-N-G-infected Sf9 cells. B. Identification of total proteins with polyclonal anti-RVFV-MP12 primary antibodies; left - negative Sf9 cells; right - rBac-N-G-infected Sf9 cells. 


\section{Purification and characterization of the RVFV VLPs}

To observe the RVFV VLPs that were packaged by the recombinant virus, we purified the VLPs by SDGC. After purification, a white target band was present between the 40 and $60 \%$ sucrose concentrations, which was expected to be the distribution zone of the VLPs in the sucrose gradient (Figure 5A). To further determine whether the expressed N, GI and G2 proteins of RVFV were packaged properly into the VLPS, we visualized the purified VLPs by TEM. It was found that the prepared VLPs were round and spherical, with an envelope of approximately $80-120 \mathrm{~nm}$ in diameter. The VLPs were consistent in morphology and structure with previously reported RVFV (Figure 5B). These results further indicate the successful production of RVFV VLPs, which may be used for relevant research such as downstream immunization experiments.

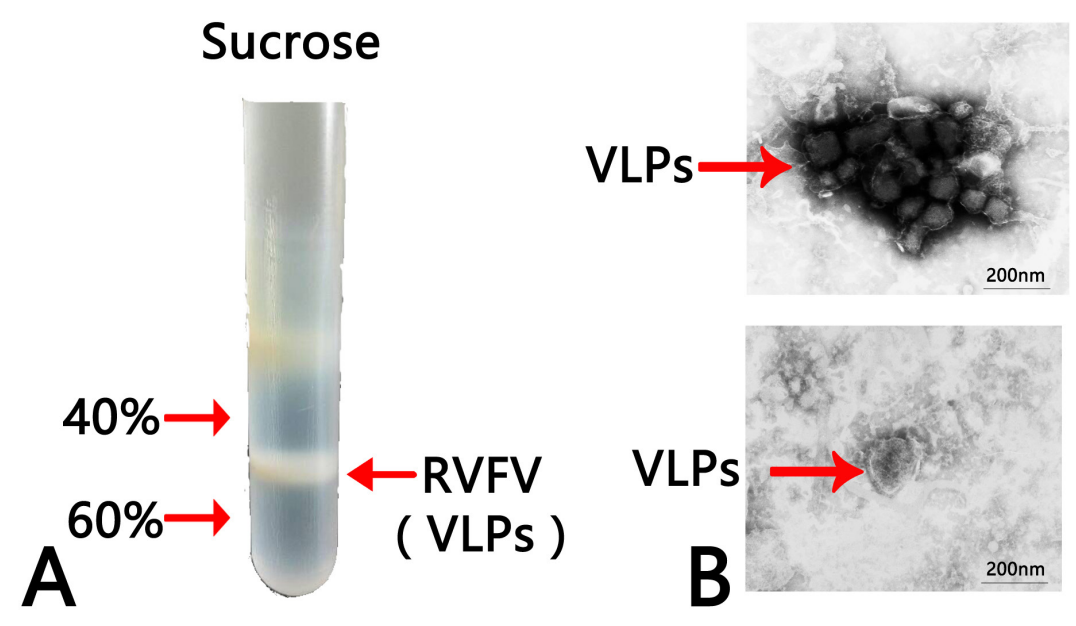

Figure 5. Purification and electron microscopy identification of Rift Valley fever virus-like particles (RVFV VLPs). A. Stratification of RVFV VLPs after sucrose density gradient centrifugation. B. Identification of purified RVFV VLPs by transmission electron microscopy.

\section{DISCUSSION}

RVF can spread through mosquitoes and aerosols, and has a mortality rate of $1 \%$. However, there has been an upward trend in the mortality rate during recent RFV epidemics (Ahmed et al., 2009), and this has drawn worldwide attention. To prevent RVFV infection, the vaccines that are currently used for humans include attenuated live vaccines, inactivated vaccines, recombinant virus vaccines, and chimeric virus vaccines. Nevertheless, these currently available vaccines have inherent disadvantages that have limited their application. Thus, to date, commercialized vaccines have been unavailable for human use, and there is a serious lack of research related to new efficient RVFV vaccine approaches. Therefore, there is an urgent need to explore new types of RVFV vaccines for the effective prevention and emergency response to RVFV outbreaks. In the current study, we used a baculovirus expression system to prepare RVFV VLPs, and the obtained VLPs displayed the typical virus-like morphology of RVFV. Moreover, the $\mathrm{N}$ and $\mathrm{G}$ viral proteins showed preferable reactions with their corresponding antibodies. More importantly, the VLPS 
packaged by this method showed high efficiency, thus providing support for their future application in novel vaccines.

In recent years, VLPs have demonstrated the following advantages over conventional whole virus vaccines: 1) high biosafety as the lack of viral nucleic acids avoids autonomous replication, and thereby eliminates the possibility of genetic recombination or the reassortment and reversion of virulence; 2) highly repetitive and orderly arrangement of surface antigens; 3) maintenance of native conformation of viral antigens, allowing them to be easily recognized by the immune system; 4) allowance for the incorporation of exogenous proteins; and 5) the ability to distinguish natural infection from immunity in animals (Crisci et al., 2012).

Depending on their size, electric potential, and other properties, VLPs can effectively activate antigen-presenting cells and B lymphocytes (Lenz et al., 2001; Storni et al., 2002). Furthermore, VLPS are able to undergo efficient antigen processing and presentation through either major histocompatibility complex class I or class II molecules, thereby inducing strong humoral and cellular immune responses (Bachmann et al., 1996; Pejawar-Gaddy et al., 2010; Win et al., 2011; Liu et al., 2013). Moreover, VLPs can directly induce dendritic cell maturation, and thus positively regulate costimulatory molecule expression and cytokine secretion, further activating CD8 ${ }^{+} \mathrm{T}$ lymphocytes (Bosio et al., 2004; Yang et al., 2004). Three VLP vaccines have thus far been approved for human use: the bivalent human papillomavirus (HPV) vaccine (Cervarix, GlaxoSmithKline, USA), the quadrivalent HPV vaccine (Merck, USA), and the hepatitis B vaccine (Merck) (Kushnir et al., 2012). Additionally, the VLP vaccine Hecolin, which was developed by Innovax Biotech (Xiamen, China) for the prevention of hepatitis E viral infection, was approved in China in 2011. In the veterinary field, market approval has been obtained for porcine circovirus type 2 VLPs (Intervet International, Netherlands) (Yin et al., 2010), whereas VLPs of other animal viruses such as those of the avian flu virus (Lee et al., 2011), foot-and-mouth disease virus (Guo et al., 2013), and bluetongue virus (Roy, 2003) have also shown the potential for commercialization. VLP vaccines for various other viruses remain under development or are currently in clinical trials (Chackerian, 2007). These prior studies highlight the broad application prospects of VLPs as vaccines. Despite this, few studies have reported on RVFV VLPs (Liu et al., 2008; de Boer et al., 2010). In the present study, for the first time, we prepared RVFV VLPs using the $S$ and M protein genes from the highly immunogenic wild-type RVFV prototype strain ZH501 in attempt to develop a potential new RVF vaccine with the desired immunogenicity.

Akahata et al. (2010) have recently developed a eukaryotic expression vector (CMV/R-C-E) using the structural gene of the chikungunya virus (CHIKV, Alphavirus) and C-E3-E2-6K-E1. CMV/ R-C-E was able to express VLPs in 293F cells and these VLPs could be utilized as immunogens. Immunization experiments showed that CHIKV VLPS stimulated BALB/c mice to produce neutralizing antibodies and produced cross-immunity against a variety of CHIKV strains. CHIKV VLP-immunized monkeys also produced high levels of neutralizing antibodies and resisted lethal attacks by $\mathrm{CHIKV}$. A high immune protection rate of $100 \%$ was observed in the immunized animals indicating that the CHIKV VLPs were strongly immunogenic and immunoprotective, and thus, they could be used as novel vaccines. Based on the successful results with CHIKV VLPs, in the present study, we recombined the structural genes of RVFV ( $S$ and $M$ segments) into the functional region of the polyhedrin gene in baculovirus. This recombinant baculovirus, rBac-N-G, was infected into Sf9 insect cells, which successfully generated RVFV VLPs. The generation of RVFV VLPs using the bacteria to baculovirus/insect cell (Bac to Bac/IC) system is advantageous because of its small host range, high safety, high expression level, post-translational modifications, complete biological 
activity, and large-scale cultivation capabilities. All of these factors lay the foundation for the further development of a commercialized candidate RVFV vaccine for human use.

The present study demonstrated the successful generation of RVFV VLPs by the co expression of the $\mathrm{N}$ and $\mathrm{G}$ proteins using the Bac to Bac/lC system, which provides a good basis for future research into new VLP-based vaccines against RVFV. To further improve the production and immunogenicity of the RVFV VLPs described herein, future studies will seek to optimize the VLP preparation conditions, including the $\mathrm{MOI}$, cell culture temperature, incubation time, and potentially the use of suspension cell cultures among other aspects. With respect to immunogenicity, it will be necessary to optimize the combination of these VLPs with immunostimulatory adjuvants, including common and novel adjuvants, to further lay the groundwork for the use of these VLPs in RVFV vaccines.

\section{Conflicts of interest}

The authors declare no conflict of interest.

\section{ACKNOWLEDGMENTS}

Research supported by the National Key Technology R\&D Program - Monitoring and Control Technology Research on Cross-Border Spread of Foreign Animal Diseases by Wildlife Animals (\#2013BAD12B04), and the China Postdoctoral Science Foundation - Research on VirusLike Particle-Based Vaccine Candidate for Rift Valley Fever (\#2013M541089).

\section{REFERENCES}

Ahmed J, Bouloy M, Ergonul O, Fooks A, et al. (2009). International network for capacity building for the control of emerging viral vector-borne zoonotic diseases: ARBO-ZOONET. Euro Surveill. 14: 12.

Akahata W, Yang ZY, Andersen H, Sun S, et al. (2010). A virus-like particle vaccine for epidemic Chikungunya virus protects nonhuman primates against infection. Nat. Med. 16: 334-338.http://dx.doi.org/10.1038/nm.2105

Bachmann MF, Lutz MB, Layton GT, Harris SJ, et al. (1996). Dendritic cells process exogenous viral proteins and viruslike particles for class I presentation to CD8+ cytotoxic T lymphocytes. Eur. J. Immunol. 26: 2595-2600.http://dx.doi. org/10.1002/eji.1830261109

Bosio CM, Moore BD, Warfield KL, Ruthel G, et al. (2004). Ebola and Marburg virus-like particles activate human myeloid dendritic cells. Virology 326: 280-287.http://dx.doi.org/10.1016/j.virol.2004.05.025

Caplen H, Peters CJ and Bishop DH (1985). Mutagen-directed attenuation of Rift Valley fever virus as a method for vaccine development. J. Gen. Virol. 66: 2271-2277.http://dx.doi.org/10.1099/0022-1317-66-10-2271

Chackerian B (2007). Virus-like particles: flexible platforms for vaccine development. Expert Rev. Vaccines 6: 381-390.http:// dx.doi.org/10.1586/14760584.6.3.381

Conraths FJ, Peters M and Beer M (2013). Schmallenberg virus, a novel orthobunyavirus infection in ruminants in Europe: potential global impact and preventive measures. N. Z. Vet. J. 61: 63-67.http://dx.doi.org/10.1080/00480169.2012.738403

Crisci E, Bárcena J and Montoya M (2012). Virus-like particles: the new frontier of vaccines for animal viral infections. Vet. Immunol. Immunopathol. 148: 211-225.http://dx.doi.org/10.1016/j.vetimm.2012.04.026

de Boer SM, Kortekaas J, Antonis AF, Kant J, et al. (2010). Rift Valley fever virus subunit vaccines confer complete protection against a lethal virus challenge. Vaccine 28: 2330-2339.http://dx.doi.org/10.1016/j.vaccine.2009.12.062

Daubney R and Hudson JR (1931). Enzootic hepatitis or Rift Valley fever: an undescribed virus disease of sheep cattle and man from east Africa. J. Path. Bact. 34: 545-579. http://dx.doi.org/10.1002/path.1700340418

Guo HC, Sun SQ, Jin Y, Yang SL, et al. (2013). Foot-and-mouth disease virus-like particles produced by a SUMO fusion protein system in Escherichia coli induce potent protective immune responses in guinea pigs, swine and cattle. Vet. Res. 44: 48.http://dx.doi.org/10.1186/1297-9716-44-48

Ikegami T (2012). Molecular biology and genetic diversity of Rift Valley fever virus. Antiviral Res. 95: 293-310.http://dx.doi. org/10.1016/j.antiviral.2012.06.001 
Kortekaas J (2014). One Health approach to Rift Valley fever vaccine development. Antiviral Res. 106: 24-32.http://dx.doi. org/10.1016/j.antiviral.2014.03.008

Kortekaas J, de Boer SM, Kant J, Vloet RP, et al. (2010). Rift Valley fever virus immunity provided by a paramyxovirus vaccine vector. Vaccine 28: 4394-4401.http://dx.doi.org/10.1016/j.vaccine.2010.04.048

Kortekaas J, Antonis AF, Kant J, Vloet RP, et al. (2012). Efficacy of three candidate Rift Valley fever vaccines in sheep. Vaccine 30: 3423-3429.http://dx.doi.org/10.1016/j.vaccine.2012.03.027

Kushnir N, Streatfield SJ and Yusibov V (2012). Virus-like particles as a highly efficient vaccine platform: diversity of targets and production systems and advances in clinical development. Vaccine 31: 58-83.http://dx.doi.org/10.1016/j. vaccine.2012.10.083

LaBeaud AD, Muchiri EM, Ndzovu M, Mwanje MT, et al. (2008). Interepidemic Rift Valley fever virus seropositivity, northeastern Kenya. Emerg. Infect. Dis. 14: 1240-1246.http://dx.doi.org/10.3201/eid1408.080082

Lee DH, Park JK, Lee YN, Song JM, et al. (2011). H9N2 avian influenza virus-like particle vaccine provides protective immunity and a strategy for the differentiation of infected from vaccinated animals. Vaccine 29: 4003-4007.http://dx.doi. org/10.1016/j.vaccine.2011.03.067

Lenz P, Day PM, Pang YY, Frye SA, et al. (2001). Papillomavirus-like particles induce acute activation of dendritic cells. J. Immunol. 166: 5346-5355.http://dx.doi.org/10.4049/jimmunol.166.9.5346

Liu F, Wu X, Li L, Ge S, et al. (2013). Virus-like particles: promising platforms with characteristics of DIVA for veterinary vaccine design. Comp. Immunol. Microbiol. Infect. Dis. 36: 343-352.http://dx.doi.org/10.1016/j.cimid.2013.02.002

Liu L, Celma CC and Roy P (2008). Rift Valley fever virus structural proteins: expression, characterization and assembly of recombinant proteins. Virol. J. 5: 82.http://dx.doi.org/10.1186/1743-422X-5-82

López-Gil E, Lorenzo G, Hevia E, Borrego B, et al. (2013). A single immunization with MVA expressing GnGc glycoproteins promotes epitope-specific CD8+-T cell activation and protects immune-competent mice against a lethal RVFV infection. PLoS Negl. Trop. Dis. 7: e2309.http://dx.doi.org/10.1371/journal.pntd.0002309

Muller R, Saluzzo JF, Lopez N, Dreier T, et al. (1995). Characterization of clone 13, a naturally attenuated avirulent isolate of Rift Valley fever virus, which is altered in the small segment. Am. J. Trop. Med. Hyg. 53: 405-411.

Mundel B and Gear J (1951). Rift valley fever; I. The occurrence of human cases in Johannesburg. S. Afr. Med. J. 25: 797-800.

Pejawar-Gaddy S, Rajawat Y, Hilioti Z, Xue J, et al. (2010). Generation of a tumor vaccine candidate based on conjugation of a MUC1 peptide to polyionic papillomavirus virus-like particles. Cancer Immunol. Immunother. 59: 1685-1696.http://dx.doi. org/10.1007/s00262-010-0895-0

Randall R, Gibbs CJ Jr, Aulisio CG, Binn LN, et al. (1962). The development of a formalin-killed Rift Valley fever virus vaccine for use in man. J. Immunol. 89: 660-671.

Roy P (2003). Nature and duration of protective immunity to bluetongue virus infection. Dev. Biol. (Basel) 114: 169-183.

Rusnak JM, Gibbs P, Boudreau E, Clizbe DP, et al. (2011). Immunogenicity and safety of an inactivated Rift Valley fever vaccine in a 19-year study. Vaccine 29: 3222-3229.http://dx.doi.org/10.1016/j.vaccine.2011.02.037

Seufi AM and Galal FH (2010). Role of Culex and Anopheles mosquito species as potential vectors of rift valley fever virus in Sudan outbreak, 2007. BMC Infect. Dis. 10: 65.http://dx.doi.org/10.1186/1471-2334-10-65

Storni T, Lechner F, Erdmann I, Bächi T, et al. (2002). Critical role for activation of antigen-presenting cells in priming of cytotoxic T cell responses after vaccination with virus-like particles. J. Immunol. 168: 2880-2886.http://dx.doi.org/10.4049/ ïmmunol.168.6.2880

Win SJ, Ward VK, Dunbar PR, Young SL, et al. (2011). Cross-presentation of epitopes on virus-like particles via the MHC I receptor recycling pathway. Immunol. Cell Biol. 89: 681-688.http://dx.doi.org/10.1038/icb.2010.161

Woods CW, Karpati AM, Grein T, McCarthy N, et al.; World Health Organization Hemorrhagic Fever Task Force (2002). An outbreak of Rift Valley fever in Northeastern Kenya, 1997-98. Emerg. Infect. Dis. 8: 138-144.http://dx.doi.org/10.3201/ eid0802.010023

World Health Organization (2012). Rift Valley Fever in Mauritania. http://www.who.int/csr/don/2012_11_01/en. Accessed November 1, 2015.

Yang R, Murillo FM, Cui H, Blosser R, et al. (2004). Papillomavirus-like particles stimulate murine bone marrow-derived dendritic cells to produce alpha interferon and Th1 immune responses via MyD88. J. Virol. 78: 11152-11160.http://dx.doi. org/10.1128/JVI.78.20.11152-11160.2004

Yin S, Sun S, Yang S, Shang Y, et al. (2010). Self-assembly of virus-like particles of porcine circovirus type 2 capsid protein expressed from Escherichia coli. Virol. J. 7: 166.http://dx.doi.org/10.1186/1743-422X-7-166 